Perceived Risk, Trust, and Democracy

\author{
Paul Slovic \\ Decision Research \\ 1201 Oak Street \\ Eugene, Oregon 97401
}

\begin{abstract}
Risk management has become increasingly politicized and contentious. Polarized views, controversy, and overt conflict have become pervasive. Risk perception research has recently begun to provide a new perspective on this problem. Distrust in risk analysis and risk management plays a central role in this perspective. According to this view, the conflicts and controversies surrounding risk management are not due to public ignorance or irrationality but, instead, are seen as a side effect of our remarkable form of participatory democracy, amplified by powerful technological and social changes that systematically destroy trust. Recognizing the importance of trust and understanding the "dynamics of the system" that destroys trust has vast implications for how we approach risk management in the future.
\end{abstract}

Key words: Perceived risk, trust, risk management, risk communication, risk analysis 


\section{Perceived Risk, Trust, and Democracy ${ }^{1}$}

My objective in this paper is to examine the interplay between several remarkable trends within our society pertaining to the perception and management of risk.

The first of these trends is the fact that during a twenty-year period during which our society has grown healthier and safer on average and spent billions of dollars and immense effort to become so, the American public has become more-rather than less - concerned about risk. We have come to perceive ourselves as increasingly vulnerable to life's hazards and to believe that our land, air, and water are more contaminated by toxic substances than ever before.

A second dramatic trend that I believe is closely related to the first is the fact that risk assessment and risk management-like many other facets of our society - have become much more contentious. Polarized views, controversy and overt conflict have become pervasive. Frustrated scientists and industrialists castigate the public for behaviors they judge to be based on irrationality or ignorance. Members of the public feel similarly antagonistic toward industry and government. A desperate search for salvation through risk communication efforts began in the mid-1980s yet, despite some localized successes, this effort has not stemmed the major conflicts or reduced much of the dissatisfaction with risk management. 
Early studies of risk perception demonstrated that the public's concerns could not simply be blamed on ignorance or irrationality. Instead, research showed that many of the public's reactions to risk could be attributed to a sensitivity to technical, social and psychological qualities of hazards that were not well-modeled in technical risk assessments (e.g., qualities such as uncertainty in risk assessments, perceived inequity in the distribution of risks and benefits, and aversion to being exposed to risks that were involuntary, not under one's control, or dreaded). The important role of social values in risk perception and risk acceptance thus became apparent. ${ }^{(1)}$

More recently, another important aspect of the risk-perception problem has come to be recognized. This is the role of trust. In recent years there have been numerous articles and surveys pointing out the importance of trust in risk management and documenting the extreme distrust we now have in many of the individuals, industries, and institutions responsible for risk management. This pervasive distrust has also been shown to be strongly linked to risk perception and to political activism to reduce risk. $^{(2-6)}$

In this paper I shall look beyond current perceptions of risk and distrust and attempt to explain how they came to be this way. My explanation begins with the idiosyncrasies of individual human minds, befitting my background as a psychologist. However, individual psychology is not fully adequate to account for risk perception and conflict. A broader perspective is necessary, one that 
includes the complex mix of scientific, social, political, legal, institutional, and psychological factors operating within our society's risk-management system.

\section{The Importance of Trust}

Everyone knows intuitively that trust is important for all forms of human social interaction. Perhaps because it is such a familiar concept, its importance in risk management has not been adequately appreciated. However, numerous recent studies clearly point to lack of trust as a critical factor underlying the divisive controversies that surround the management of technological hazards. ${ }^{(7-21)}$

To appreciate the importance of trust, it is instructive to compare those risks that we fear and avoid with those we casually accept. Starr ${ }^{(22)}$ has pointed to the public's lack of concern about the risks from tigers in urban zoos as evidence that acceptance of risks is strongly dependent upon confidence in risk management. Similarly, risk perception research ${ }^{(23)}$ documents that people view medical technologies based upon use of radiation and chemicals (i.e., $\mathrm{x}$-rays and prescription drugs) as high in benefit, low in risk, and clearly acceptable. However, they view industrial technologies involving radiation and chemicals (i.e., nuclear power, pesticides, industrial chemicals) as high in risk, low in benefit, and unacceptable. Although $\mathrm{x}$-rays and medicines pose significant risks, our relatively high degree of trust in the physicians who manage these devices makes them acceptable. Numerous polls have shown that the government and 
industry officials who oversee the management of nuclear power and nonmedical chemicals are not highly trusted. ${ }^{(3,24,18,6)}$

During the past several decades, the field of risk assessment has developed to impart rationality to the management of technological hazards. Risk assessment has its roots in epidemiology, toxicology, systems analysis, reliability theory, and many other disciplines. Probably more than one billion dollars has been spent to conduct innumerable animal bioassays and epidemiological studies to assess the human health consequences of exposure to radiation and chemicals and to develop probabilistic risk analyses for nuclear reactors, dams, hazardous waste treatment, and other engineered facilities. The Environmental Protection Agency, the Nuclear Regulatory Commission, and numerous other government agencies have made risk assessment the centerpiece of their regulatory efforts..$^{(25-27)}$

It is now evident that public perceptions and acceptance of risk from nuclear and chemical technologies are not much influenced by technical risk assessments. Nowhere is this phenomenon more dramatically illustrated than in the unsuccessful struggle, across many years, to dispose of the accumulating volume of spent fuel from the nation's commercial nuclear reactors. The Department of Energy's program to establish a national repository has been stymied by overwhelming public opposition, fueled by public perceptions that the risks are immense and unacceptable. ${ }^{(6)}$ These perceptions stand in stark contrast to the prevailing view of the technical community, whose risk 
assessments assert that nuclear wastes can be disposed of safely in an underground repository (see Table I).

\section{Insert Table I here}

Public fears and opposition to nuclear waste disposal plans can be seen as a "crisis in confidence," a profound breakdown of trust in the scientific, governmental, and industrial managers of nuclear technologies. It is clear that the Department of Energy and the U.S. Congress have not adequately appreciated the importance of (dis)trust in the failure of the nuclear waste program, nor have they recognized the implications of this situation. ${ }^{(6,21)}$ Analogous crises of confidence can be demonstrated in numerous controversies surrounding exposures to chemicals. Again, risk assessment, in these situations based primarily upon toxicology, is often impotent when it comes to resolving conflict about chemical risks. ${ }^{(28)}$

Because it is impossible to exclude the public in our uniquely participatory democracy, the response of industry and government to this crisis of confidence has been to turn to the young and still primitive field of risk communication in search of methods to bring experts and laypeople into alignment and make conflicts over technological decisions easier to resolve-see, e.g., William Ruckelshaus' stirring speeches on this topic, ${ }^{(26,29)}$ the National Academic of Sciences report on risk communication, ${ }^{(30)}$ and the Chemical Manufacturer's Association communication manual for plant managers. ${ }^{(31)}$ Although attention to communication can prevent blunders that 
exacerbate conflict, there is rather little evidence that risk communication has made any significant contribution to reducing the gap between technical risk assessments and public perceptions or to facilitating decisions about nuclear waste or other major sources of risk conflict. The limited effectiveness of risk communication efforts can be attributed to the lack of trust. If you trust the risk manager, communication is relatively easy. If trust is lacking, no form or process of communication will be satisfactory. ${ }^{(32)}$ Thus trust is more fundamental to conflict resolution than is risk communication.

\section{Creation and Destruction of Trust}

One of the most fundamental qualities of trust has been known for ages. Trust is fragile. It is typically created rather slowly, but it can be destroyed in an instant—by a single mishap or mistake. Thus, once trust is lost, it may take a long time to rebuild it to its former state. In some instances, lost trust may never be regained. Abraham Lincoln understood this quality. In a letter to Alexander McClure he observed: "If you once forfeit the confidence of your fellow citizens, you can never regain their respect and esteem" [italics added].

The asymmetry between the difficulty of creating trust and the ease of destroying it has been studied by social psychologists within the domain of interpersonal perception. For example, Rothbart and Park $^{(33)}$ had people rate 150 descriptive traits (adventurous, gentle, lazy, trustworthy, etc.) in terms of the number of relevant behavioral instances necessary to establish or disconfirm the trait. Favorable traits (like trustworthiness) were judged to be hard to acquire 
(many behavioral instances needed) and easy to lose. Unfavorable traits were judged to be easier to acquire and harder to lose. The number of behavioral instances required to disconfirm a negative quality (e.g., dishonesty) was greater than the number required to disconfirm a positive trait. As Abraham Lincoln might have predicted, trustworthiness stood out among the 150 traits as requiring a relatively large number of confirming instances to establish the trait and a relatively small number of relevant instances to disconfirm it. (Note that data here were judgments of the number of instances that would be required as opposed to data documenting the number of instances that actually confirmed or disconfirmed a trait.)

The fact that trust is easier to destroy than to create reflects certain fundamental mechanisms of human psychology that I shall call "the asymmetry principle." When it comes to winning trust, the playing field is not level. It is tilted toward distrust for each of the following reasons:

1. Negative (trust-destroying) events are more visible or noticeable than positive (trust-building) events. Negative events often take the form of specific, well-defined incidents such as accidents, lies, discoveries of errors or other mismanagement. Positive events, while sometimes visible, more often are fuzzy or indistinct. For example, how many positive events are represented by the safe operation of a nuclear power plant for one day? Is this one event? dozens of events? hundreds? There is no precise answer. When events are invisible or 
poorly defined, they carry little or no weight in shaping our attitudes and opinions.

2. When events do come to our attention, negative (trust-destroying) events carry much greater weight than positive events. This important psychological tendency is illustrated by a study in which my colleagues and I asked 103 college students to rate the impact on trust of 45 hypothetical news events pertaining to the management of a large nuclear power plant in their community. ${ }^{(34)}$ Some of these events were designed to be trust increasing, such as

- There have been no reported safety problems at the plant during the past year.

- There is careful selection and training of employees at the plant.

- Plant managers live nearby the plant.

- The county medical examiner reports that the health of people living near the plant is better than the average for the region.

Other events were designed to be trust decreasing, such as

- A potential safety problem was found to have been covered up by plant officials.

- Plant safety inspections are delayed in order to meet the electricity production quota for the month.

- A nuclear power plant in another state has a serious accident.

- The county medical examiner reports that the health of people living near the plant is worse than the average for the region. 
The respondents were asked to indicate, for each event, whether their trust in the management of the plant would be increased or decreased upon learning of that event. After doing this, they rated how strongly their trust would be affected by the event on a scale ranging from 1 (very small impact on trust) to 7 (very powerful impact on trust). The percentages of Category 7 ratings, shown in Figure 1, dramatically demonstrate that negative events are seen as far more likely to have a powerful effect on trust than are positive events.

Insert Figure 1 here

The data shown in Table II are typical. The negative event, reporting plant neighbors' health as worse than average, was rated 6 or 7 on the impact scale by 50.0 per cent of the respondents. A matched event, reporting neighbors' health to be better than average, was rated 6 or 7 by only 18.3 per cent of the respondents.

\section{Insert Table II here}

There was only one event perceived to have any substantial impact on increasing trust. This event stated: “An advisory board of local citizens and environmentalists is established to monitor the plant and is given legal authority to shut the plant down if they believe it to be unsafe."

This strong delegation of authority to the local public was rated 6 or 7 on the impact scale by 38.4 per cent of the respondents. Although this was a far 
stronger showing than for any other positive event, it would have been a rather average performance in the distribution of impacts for negative events.

The reasons for the greater impact of trust-destroying incidents are complex and I shall not discuss them here except to note that the importance of an event is at least in part related to its frequency (or rarity). An accident in a nuclear plant is more informative with regard to risk, than is a day (or even a large number of days) without an accident. Thus, in systems where we are concerned about low-probability/high consequence events, problematic events will increase our perceptions of risk to a much greater degree than favorable events will decrease them.

3. Adding fuel to the fire of asymmetry is yet another idiosyncracy of human psychology—sources of bad (trust-destroying) news tend to be seen as more credible than sources of good news. For example, in several studies of what we call "intuitive toxicology," ${ }^{(35)}$ we have examined people's confidence in the ability of animal studies to predict human health effects from chemicals. In general, confidence in the validity of animal studies is not particularly high. However, when told that a study has found that a chemical is carcinogenic in animals, people express considerable confidence in the validity of this study for predicting health effects in humans. Regulators respond like the public. Positive (bad news) evidence from animal bioassays is presumptive evidence of risk to humans; negative evidence (e.g., the chemical was not found to be harmful) carries little weight. ${ }^{(36)}$ 
4. Another important psychological tendency is that distrust, once initiated, tends to reinforce and perpetuate distrust. This occurs in two ways. First, distrust tends to inhibit the kinds of personal contacts and experiences that are necessary to overcome distrust. By avoiding others whose motives or actions we distrust, we never get to see that these people are competent, wellmeaning, and trustworthy. Second, initial trust or distrust colors our interpretation of events, thus reinforcing our prior beliefs. Persons who trusted the nuclear power industry saw the events at Three Mile Island as demonstrating the soundness of the "defense in depth" principle, noting that the multiple safety systems shut the plant down and contained most of its radiation. Persons who distrusted nuclear power prior to the accident took an entirely different message from the same events, perceiving that those in charge did not understand what was wrong or how to fix it and that catastrophe was averted only by sheer luck.

\section{“The System Destroys Trust"}

Thus far I have been discussing the psychological tendencies that create and reinforce distrust in situations of risk. Appreciation of those psychological principles leads us toward a new perspective on risk perception, trust, and conflict. Conflicts and controversies surrounding risk management are not due to public irrationality or ignorance but, instead, can be seen as expected side effects of these psychological tendencies, interacting with our remarkable form of participatory Democratic government, and amplified by certain powerful technological and social changes in our society. The technological change has 
given the electronic and print media the capability (effectively utilized) of informing us of news from all over the world —often right as it happens. Moreover, just as individuals give greater weight and attention to negative events, so do the news media. Much of what the media reports is bad (trustdestroying) news. ${ }^{(37)}$ This is convincingly demonstrated by Koren and Klein, ${ }^{(38)}$ who compared the rates of newspaper reporting of two studies, one providing bad news and one good news, published back to back in the March 20, 1991 issue of the Journal of the American Medical Association. Both studies examined the link between radiation exposure and cancer. The bad news study showed an increased risk to leukemia in white men working at the Oak Risk National Laboratory. The good news study failed to show an increased risk of cancer in people residing near nuclear facilities. Koren and Klein found that subsequent newspaper coverage was far greater for the study showing increased risk.

The second important change, a social phenomenon, is the rise of powerful special interest groups-well funded (by a fearful public) and sophisticated in using their own experts and the media to communicate their concerns and their distrust to the public in order to influence risk policy debates and decisions. ${ }^{(39)}$ The social problem is compounded by the fact that we tend to manage our risks within an adversarial legal system that pits expert vs. expert, contradicting each other's risk assessments and further destroying the public trust. 
The young science of risk assessment is too fragile, too indirect to prevail in such a hostile atmosphere. Scientific analysis of risks cannot allay our fears of low-probability catastrophes or delayed cancers unless we trust the system. In the absence of trust, science (and risk assessment) can only feed distrust, by uncovering more bad news. A single study demonstrating an association between exposure to chemicals or radiation and some adverse health effect cannot easily be offset by numerous studies failing to find such an association. Thus, for example, the more studies that are conducted looking for effects of electric and magnetic fields or other difficult to evaluate hazards, the more likely it is that these studies will increase public concerns, even if the majority of these studies fail to find any association with ill health..$^{(40-41)}$ In short, risk-assessment studies tend to increase perceived risk.

\section{Where Next? Risk and Democracy}

Although the study of risk perception and trust has not yet led to a solution to our risk-management problems, it appears to be leading to a more adequate diagnosis of the root causes of risk concerns and risk conflicts. As we begin to understand the complexity of risk conflicts, we recognize the need for new approaches to risk management. The road branches in two very different directions. $^{(42)}$ One direction leads towards less public participation and more centralized control. One might call this the French model. France leads the world in the percentage of electricity generated by nuclear power ( 73 per cent in 1991, compared to 21 per cent for the U.S.). France, like the U.S., was rocked 
by strong anti-nuclear protests during the late 1970 s but the state acted forcefully to repress these protests and the anti-nuclear movement never gained favor with the political parties in power. Today, surprisingly, the perception of risk from nuclear power remains extremely high in France - as high as in the U.S., according to national surveys my colleagues and I recently conducted in both countries. However, French citizens, while recognizing that they have little control over risks to their health and safety, have a high degree of trust in their government and in the experts who design and operate nuclear power plants. Americans, in contrast, combine their similarly high degree of perceived risk with a distrust of government, science, and industry and a belief that they do have some ability to control risks. In fact, the American system does provide individual citizens and citizen groups considerable freedom to intervene in administrative proceedings, to question expert judgments of government agencies, and to force changes in policy through litigation. ${ }^{(43)}$

Political scientists have recognized that, in a climate of strong distrust, the French approach, in which policy formation and implementation is not accessible to public intervention, is expedient. ${ }^{(44)}$ Campbell, ${ }^{(45)}$ for example, argues that formal democratic institutions providing political access to nuclear critics may be fundamentally incompatible with commercial success of nuclear power.

What works in France, however, is unlikely to be achievable in the U.S. The French nuclear power program is run by the state, not private industry. 
Electricité de France has long had a strong reputation for being competent and putting service above profits. The French have a tradition of looking to a scientific elite for guidance in policy matters. Jasper, ${ }^{(46)}$ noting that the word as well as the image of a "technocrat" arose in France, observed that "Perhaps no other political system provides as large a role for people to exercise power on the basis of technical training and certification." (46, p. 83)

America, since Thomas Jefferson, has had a different approach to democracy and it is not surprising that attempts to restrict citizens' rights to intervene directly in national risk-management policies have been vigorously opposed. A recent example is the unsuccessful attempt in Congress to strip the state of Nevada of its rights to issue environmental and safety permits for nuclear waste studies at Yucca Mountain. ${ }^{(47)}$

Given that the French approach is not likely to be acceptable in the U.S., restoration of trust may require a degree of openness and involvement with the public that goes far beyond public relations and "two-way communication" to encompass levels of power sharing and public participation in decision making and that have rarely been attempted. ${ }^{(48-50)}$ Even this, however, is no guarantee of success. ${ }^{(51-52)}$ In many situations, we may have to recognize that relationships are so poisoned that trust and conflict resolution cannot realistically be achieved in the short run. The bitter conflict over the proposed nuclear waste repository in Nevada is a prime example of such a situation. To preserve the form of 
democracy we value so highly, we will need to develop ways to work constructively in situations where we cannot assume that trust is attainable. ${ }^{(15)}$

We have a long way to go in improving our risk-management processes. Although we have expended massive amounts of time, money, and resources on scientific studies designed to identify and quantify risks, we have failed to expend the effort needed to learn how to manage the hazards that science is so good at identifying. Gerald Jacob ${ }^{(53)}$ frames the challenge well in the context of nuclear waste disposal, and his words are also relevant to many other risk problems:

While everyone can appreciate that a complex, highly sophisticated engineering is required to safely store nuclear materials for thousands of years, few have appreciated the political requirements necessary to design and implement such a solution. While vast resources have been expended on developing complex and sophisticated technologies, the equally sophisticated political processes and institutions required to develop a credible and legitimate strategy for nuclear waste management have not been developed. The history of high-level radioactive waste management describes repeated failure to recognize the need for institutional reform and reconstruction. ${ }^{(53, \text { p. } 164)}$

Some may view the analysis in this paper as a depressing one. I do not. Understanding the root causes of social conflict and recognizing the need to create better risk-management processes are essential first steps toward 
improving the situation. It is far more depressing, in my view, to fail to understand the complex psychological, social, cultural, and political forces that dictate the successes and failures of risk management. 


\section{Endnote}

1 This is a revised version of the address given upon receipt of the

Distinguished Contribution Award of the Society for Risk Analysis in

Baltimore in December, 1991. Preparation of this paper was supported by the

Alfred P. Sloan Foundation, the Electric Power Research Institute, and the

National Science Foundation under Grant No. SES-91-10592. I wish to thank

my colleagues at Decision Research for their contributions to the ideas and

work underlying this paper. Jim Flynn, C.K. Mertz, and Leisha Mullican

deserve special thanks in this regard. Marc Poumadere and Claire Mays assisted

in the collection of the French data reported here. Howard Kunreuther provided

valuable comments on the manuscript. 


\section{References}

1. Slovic, P. (1987). Perception of risk. Science, 236, 280-285.

2. Bord, R. J., and O'Connor, R. E. (1990). Risk communication, knowledge, and attitudes: Explaining reactions to a technology perceived as risky. $\underline{\text { Risk }}$ Analysis, $10,499-506$.

3. Flynn, J., Burns, W., Mertz, C. K., and Slovic, P. (1992). Trust as a determinant of opposition to a high-level radioactive waste repository: Analysis of a structural model. Risk Analysis, 12(3), pp. 417-429.

4. Jenkins-Smith, H. C. (1992). Culture, trust, ideology and perceptions of the risks of nuclear wastes: A causal analysis. Paper prepared for the Annual Meeting of the Society for Risk Analysis, December 6-9, San Diego, CA.

5. Mushkatel, A. H., and Pijawka, K. D. (1992). Institutional trust information, and risk perceptions: Report of findings of the Las Vegas metropolitan area survey, June 29-July 1, 1992 (NWPO-SE-055-92). Carson City, NV: Nevada Nuclear Waste Project Office.

6. Slovic, P., Flynn, J., and Layman, M. (1991). Perceived risk, trust, and the politics of nuclear waste. Science, $254,1603-1607$.

7. Bella, D. A. (1987). Engineering and erosion of trust. Journal of Professional Issues in Engineering, 113, 117-129.

8. Bella, D. A., Mosher, C. D., and Calvo, S. N. (1988a). Establishing trust: Nuclear waste disposal. Journal of Professional Issues in Engineering, 114, 40-50. 
9. Bella, D. A., Mosher, C. D., and Calvo, S. N. (1988b). Technocracy and trust: Nuclear waste controversy. Journal of Professional Issues in Engineering, 114(1), 27-39.

10. Cvetkovich, G., and Earle, T. C. (1992). Social trust and value similarity: New interpretations of risk communiction in hazard management. Paper presented at the 1992 annual meeting of the Society for Risk Analysis, San Diego, CA.

11. English, M. R. (1992). Siting low-level radioactive waste disposal facilities: The public policy dilemma. New York: Quorum.

12. Flynn, J., and Slovic, P. (1993). Nuclear wastes and public trust. Forum for Applied Research and Public Policy, 8, 92-100.

13. Freudenburg, W. (1991). Risk and recreancy: Weber, the division of labor, and the rationality of risk perceptions (Unpublished manuscript, Department of Rural Sociology, University of Wisconsin, Madison).

14. Johnson, B. B. (1992). Trust in theory: Many questions, few answers. Paper presented at the 1992 annual meeting of the Society for Risk Analysis, San Diego, CA.

15. Kasperson, R., Golding, D., and Tuler, S. (1992). Social distrust as a factor in siting hazardous facilities and communicating risks. Journal of Social Issues, 48(4), 161-187.

16. Laird, F. N. (1989). The decline of deference: The political context of risk communication. Risk Analysis, 9, 543-550. 
17. Mitchell, J. V. (1992). Perception of risk and credibility at toxic sites. Risk Analysis, $12,19-26$.

18. Pijawka, K. D., and Mushkatel, A. H. (1991/92). Public opposition to the siting of the high-level nuclear waste repository: The importance of trust. Policy Studies Review, 10(4), 180-194.

19. Rayner, S., and Cantor, R. (1987). How fair is safe enough? The cultural approach to societal technology choice. Risk Analysis, 7, 3-9.

20. Renn, O., and Levine, D. (1991). Credibility and trust in risk communication. In R. E. Kasperson, and P. J. M. Stallen (Ed.), Communicating risks to the public (pp. 175-218). Dordrecht: Kluwer Academic.

21. U.S. Department of Energy. (1992, December). Draft final report of the Secretary of Energy Advisory Board Task Force on Radioactive Waste Management. Washington, DC: Author.

22. Starr, C. (1985). Risk management, assessment, and acceptability. $\underline{\text { Risk }}$ Analysis, 5, 97-102.

23. Slovic, P. (1990). Perception of risk from radiation. In W. K. Sinclair (Ed.), Proceedings of the Twenty-fifth Annual Meeting of the National Council on Radiation Protection and Measurements. Vol 11: Radiation protection today: The NCRP at sixty years (Vol. 11, pp. 73-97). Bethesda, MD: NCRP. 
24. McCallum, D. B., Hammond, S. L., Morris, L. A., and Covello, V. T. (1990). Public knowledge and perceptions of chemical risks in six communities (Report No. 230-01-90-074). Washington, D.C.: U.S. Environmental Protection Agency.

25. Levine, S. (1984). Probabilistic risk assessment: Identifying the real risks of nuclear power. Technology Review, 87(2), 40-44.

26. Ruckelshaus, W. D. (1983). Science, risk, and public policy. Science, 221, 1026-1028.

27. U.S. Nuclear Regulatory Commission (USNRC). (1983, May). Safety goals for nuclear power plant operation (USNRC Report NUREG-0880). Washington, DC: Author.

28. Graham, J. D., Green, L. C., and Roberts, M. J. (1988). In search of safety: chemicals and cancer risk. Cambridge, MA: Harvard.

29. Ruckelshaus, W. D. (1984). Risk in a free society. Risk Analysis, 4, 157162.

30. National Research Council (NRC). (1989). Improving risk communication. Washington, DC: National Academy Press.

31. Covello, V. T., Sandman, P. M., and Slovic, P. (1988). isk communication. risk statistics, and risk comparisons: A manual for plant managers. Washington, DC: Chemical Manufacturers Association. 
32. Fessendon-Raden, J., Fitchen, J. M., and Heath, J. S. (1987). Providing risk information in communities: Factors influencing what is heard and accepted. Science, Technology, and Human Values, 12, 94-101.

33. Rothbart, J., and Park, B. (1986). On the confirmability and disconfirmability of trait concepts. Journal of Personality and Social Psychology, 50, 131-142.

34. Slovic, P., Flynn, J., Johnson, S., and Mertz, C. K. (1993). The dynamics of trust in situations of risk (Report No. 93-2). Eugene, OR: Decision Research.

35. Kraus, N., Malmfors, T., and Slovic, P. (1992). Intuitive toxicology: Expert and lay judgments of chemical risks. Risk Analysis, 12, 215-232.

36. Efron, E. (1984). The apocalyptics. New York: Simon and Schuster.

37. Lichtenberg, J., and MacLean, D. (1992). Is good news no news? The Geneva papers on risk and insurance, 17, 362-365.

38. Koren, G., and Klein, N. (1991). Bias against negative studies in newspaper reports of medical research. Journal of the American Medical Association, $266,1824-1826$.

39. Wall Street Journal. (1989). How a PR firm executed the Alar scare, October 3, pp. A1, A3.

40. MacGregor, D., Slovic, P., and Morgan, M. G. (1992). Perception of risks from electromagnetic fields: A psychometric evaluation of a risk- 
communication approach (Report No. 92-6). Eugene, OR: Decision Research.

41. Morgan, M. G., Slovic, P., Nair, I., Geisler, D., MacGregor, D., Fischhoff, B., Lincoln, D., and Florig, K. (1985). Powerline frequency electric and magnetic fields: A pilot study of risk perception. Risk Analysis, 5, 139149.

42. Fiorino, D. (1989). Technical and democratic values in risk analysis. Risk Analysis, 9, 293-299.

43. Jasanoff, S. (1986). Risk management and political culture. New York: Russell Sage Foundation.

44. Morone, J. F., and Woodhouse, E. J. (1989). The demise of nuclear energy? Lessons for a democratic control of technology. New Haven: Yale University.

45. Campbell, J. L. (1988). Collapse of an industry: Nuclear power and the contradictions of U.S. policy. Ithaca, New York: Cornell University Press.

46. Jasper, J. M. (1990). Nuclear politics: Energy and the state in the United States, Sweden, and France. Princeton, NJ: Princeton University Press.

47. Batt, T. (1992). Nevada claims victory in Yucca deal. Las Vegas ReviewJournal, July 23, pp. 1A, 3A.

48. Flynn, J., Kasperson, R., Kunreuther, H., and Slovic, P. (1992). Time to rethink nuclear waste storage. Issues in Science and Technology, 8(4), pp. $42-48$. 
49. Kunreuther, H., Fitzgerald, K., and Aarts, T. D. (1993). Siting noxious facilities: A test of the facility siting credo. Risk Analysis.13(3), 301-318.

50. Leroy, D. H., and Nadler, T. S. (1993). Negotiate way out of siting dilemmas. Forum for Applied Research and Public Policy, 8 (1, Spring), 102-107.

51. Bord, R. J. (1988). The low-level radioactive waste crisis: Is more citizen participation the answer? In M. A. Burns (Ed.), Low-level radioactive waste regulation: Science, politics, and fear (pp. 193-213). Chelsea, MI: Lewis.

52. Nelkin, D., and Pollak, M. (1979). Public participation in technological decisions: Reality or grand illusion? Technology Review, August/September, pp. 55-64.

53. Jacob, G. (1990). Site unseen: The politics of siting a nuclear waste repository. Pittsbugh: University of Pittsburgh. 
Table I. Viewpoints on the risks from nuclear waste disposal.

The following comments reflect expert viewpoints on the risks from nuclear waste disposal and the public's perceptions of these risks.

"Several years ago. .. I talked with Sir John Hill, .. .chairman of the United Kingdom's Atomic Energy Authority. 'I've never come across any industry where the public perception of the problem is so totally different from the problems as seen by those of us in the industry....,' Hill told me. In Hill's view, the problem of radioactive waste disposal was, in a technical sense, comparatively easy." (L. J. Carter, Nuclear Imperatives and Public Trust. Resources for the Future, Inc., Washington, D.C., 1987, p. 9.)

"Nuclear wastes can be sequestered with essentially no chance of any member of the public receiving a non-stochastic dose of radiation. ... Why is the public's perception of the nuclear waste issue at such odds with the experts' perception?" (A.M. Weinberg, Public Perceptions of Hazardous Technologies and Democratic Political Institutions. Paper presented at Waste Management 1989, Tucson, Arizona, 1989, pp. 1-2.)

"The fourth major reason for public misunderstanding of nuclear power is a grossly unjustified fear of the hazards from radioactive waste ... there is general agreement among those scientists involved with waste management that radioactive waste disposal is a rather trivial technical problem." (B. L. Cohen, Before It's Too Late: A Scientist's Case for Nuclear Energy. Plenum, New York, 1983, p. 119.)

"The risk is as negligible as it is possible to imagine ... It is embarrassingly easy to solve the technical problems, yet impossible to solve the political ones." (H.W. Lewis, Technological Risk. W. W. Norton, New York, 1990, pp. 245-246). 
Table II. Judged Impact of a Trust-Increasing Event and a Similar TrustDecreasing Event.

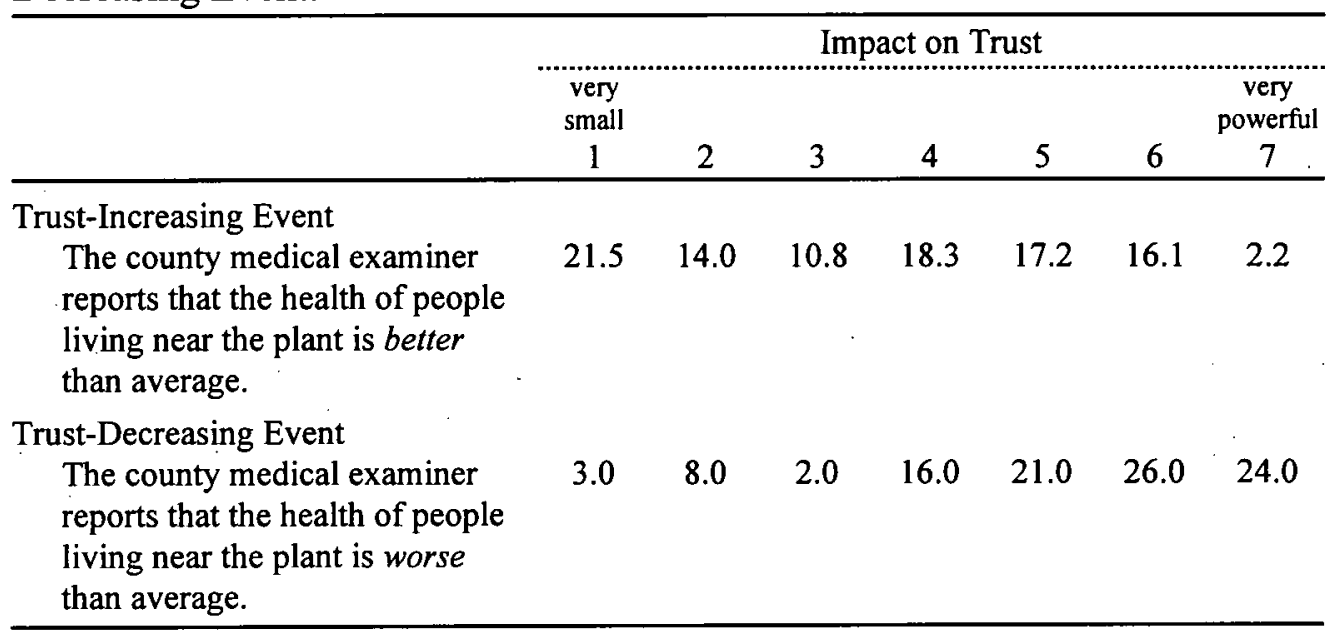

Note: Cell entries indicate the percentage of respondents in each impact rating category. 


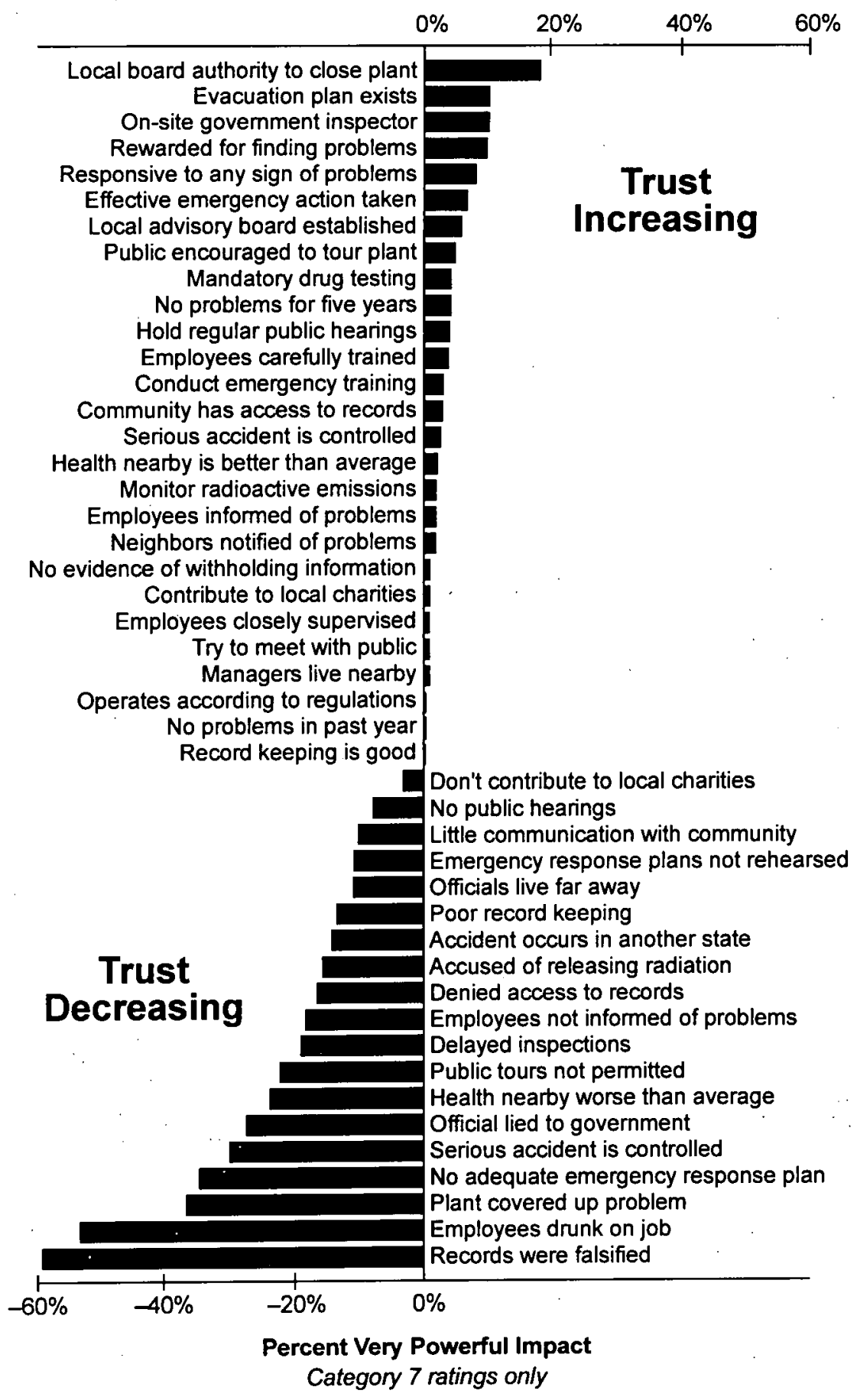

Figure 1. Differential impact of trust-increasing and trust-decreasing events. 